\title{
PRODUÇÕES CIENTÍFICAS SOBRE AFETIVIDADE NA RELAÇÃO ADULTO-CRIANÇA NO ESPAÇO DA EDUCAÇÃO INFANTIL
}

\section{SCIENTIFIC PRODUCTION ON AFFECTIVITY-CHILD RELATIONSHIP IN ADULT AREA OF EARLY CHILDHOOD EDUCATION}

\author{
Fernanda Ribeiro da Silva \\ Sílvia Adriana Rodrigues
}

\begin{abstract}
RESUMO:A pesquisa relatada no presente texto adotou como objetivo geral analisar como os trabalhos resultantes de pesquisas empíricas discutem a questão da afetividade na relação entre adultos e crianças, no ambiente da Educação Infantil, com destaque para os que usam como fundamento teórico a perspectiva walloniana do desenvolvimento humano. Configurou-se numa investigação de abordagem qualitativa, do tipo estado do conhecimento, cujo mapeamento bibliográfico em portais eletrônicos, selecionados a priori, resultou na seleção final de quatro artigos. Entre outras questões, a análise permite afirmar que a temática da afetividade, especificamente no ambiente da Educação Infantil, com o uso do referencial walloniano, é ainda pouco abordada em investigações científicas, e que as produções realizadas até o momento oferecem ricas contribuições para a área da formação de professores.
\end{abstract}

Palavras-chave: Afetividade. Estado do conhecimento. Educação Infantil. Relação adulto-criança.Teoria walloniana.

ABSTRACT:The research reported in this text adopted as a general goal to analyze the work resulting from empirical research discussing the issue of affection in the relationship between adults and children in early childhood education environment, especially those who use as a theoretical foundation the wallonian perspective of development human. Set up an investigation of qualitative approach, the type state of knowledge, whose bibliographic mapping in electronic portals, selected a priori, resulted in the final selection of four articles. Among other issues, the analysis to confirm that the theme of affection, specifically in early childhood education environment, using the wallonian reference, is still rarely addressed in scientific research, and that the productions made to date offer rich contributions the area of teacher training.

Keywords: Affectivity. State of knowledge. Childhood education. Adult-child relationship.Wallonian theory.

\section{INTRODUÇÃO}

Partimos do pressuposto de que a afetividade é um domínio funcional do ser humano que evolui ao longo do processo evolutivo e interfere em outros domínios,

Educação, Psicologia e Interfaces, v. 2, n. 1, p. 88-104, Janeiro/Abril, 2018 
como o cognitivo e o motor; com base no aparato teórico de Henri Wallon, a consideramos ainda como a capacidade, ou disposição, de os seres humanos serem afetados pelo meio (físico e social) que os circunda, bem como por disposições do corpo físico; envolve, assim, diversas tonalidades de sensações, tanto agradáveis quanto desagradáveis, as quais, por sua vez, interferem de forma mais ou menos determinante no comportamento dos sujeitos.

Diante dessa premissa, consideramos relevante o desenvolvimento de estudos teóricos e pesquisas empíricas que discutem tal questão, principalmente no âmbito da Educação Infantil, tendo em vista que a infância é a época por excelência de manifestações expressivas da afetividade de forma mais espontânea, além de ser um momento particular do desenvolvimento humano em que as experiências afetivas podem imprimir marcas mais ou menos duradouras nos modos de ser e agir das crianças.

Desse modo, a investigação a ser relatada foi desenvolvida, no formato de Trabalho de Conclusão do Curso de Pedagogia, com o intuito de analisar os trabalhos resultantes de pesquisas empíricas que estudaram a afetividade na relação entre educador e educando, no ambiente da Educação Infantil, especificamente apoiados no pressuposto walloniano. Cabe ainda apontar que os questionamentos desencadeadores foram: como os pesquisadores se apropriaram do conceito walloniano de afetividade?; os trabalhos realmente focam a relação adulto-criança ou apenas um dos sujeitos?; a relação entre educador e criança, na Educação Infantil, é evidenciada nos trabalhos como relevante para o processo de desenvolvimento e aprendizagem infantil?; as concepções de criança e infância, enfocadas nos trabalhos, correspondem às que são trazidas no pressuposto walloniano?

Nessa direção, trazemos primeiro breve discussão sobre o conceito de afetividade adotado, para, em seguida, expor o percurso metodológico escolhido para o desenvolvimento da investigação e discussão dos dados coletados, finalizando com algumas considerações em resposta às questões as quais impulsionaram a investigação.

\subsection{0 que entendemos por afetividade?}

Para responder a esse questionamento, voltamos na história do pensamento científico e, assim, percebemos que a Filosofia já estudava a questão há tempos, no

Educação, Psicologia e Interfaces, v. 2, n. 1, p. 88-104, Janeiro/Abril, 2018.

DOI: https://doi.org/10.37444/issn-2594-5343.v2i1.51 
Produções científicas sobre afetividade na relação adulto-criança no espaço da educação infantil

entanto, compreendia os afetos/emoção de maneira isolada da dimensão cognitiva do ser humano.

A cisão entre mente e emoção é uma herança do legado de Descartes, cuja visão essencialmente dualista defendia a separação de dois campos de estudo - o das Ciências Naturais e o da Filosofia; o primeiro tinha função de estudar o comportamento, enquanto o segundo almejava entender os significados e motivações dos seres humanos, ou seja, a separação entre o corpo e a mente. Descartes acreditava ainda que as emoções estão presentes desde o nascimento e não se modificam, assim, “[...] as emoções primitivas 'infantis' poderiam ser preservadas em seu estado original ou, com o desenvolvimento, deterioradas ou controladas", mas em nenhuma circunstância poderiam se tornar emoções mais refinadas (OLIVEIRA; REGO, 2003, p. 20, grifo no original).

É no século XX que surge um movimento de tentar superar essa visão, com estudos que tencionam romper com a divisão entre razão e emoção, buscando compreender o funcionamento psicológico humano integrado em toda sua complexidade; Piaget, Vygotsky e Wallon são alguns dos nomes incluídos no grupo de pessoas que procuraram estudar os processos afetivos de forma integrada. Cabe destacar que nem todos se aprofundaram em discussões específicas sobre o tema, mas, de alguma maneira, contribuíram para a compreensão do ser humano de modo monista.

Dentre os teóricos citados, o autor que dá centralidade à afetividade no processo de desenvolvimento psicológico humano é Henri Wallon; é exatamente esse entendimento que leva o presente trabalho a adotar o pressuposto walloniano como fundamentação teórica básica.

Assim, um ponto marcante na teoria walloniana é o fato de considerar que o processo de evolução humana não se fragmenta em momentos específicos para o progresso de um aspecto isolado do outro, mas ocorre por completo, uma vez que os humanos são seres totais. Nas palavras de Wallon (1998 apud MAHONEY; ALMEIDA, 2004, p. 30), “[...] as necessidades de descrição obrigam a tratar separadamente alguns grandes conjuntos funcionais, o que não deixa de ser um artifício [...]”. Assim, a separação entre as dimensões satisfaz uma necessidade de compreender em profundidade cada uma delas, mas, na dinâmica humana, elas evoluem de forma integrada.

Educação, Psicologia e Interfaces, v. 2, n. 1, p. 88-104, Janeiro/Abril, 2018 
Dessa forma, a teoria walloniana sobre o desenvolvimento psicológico humano tem como base a psicogênese, ciência que estuda "[...] as origens, isto é, a gênese dos processos psíquicos. Partindo do mais simples, do quem vem antes na cronologia de transformações por que passa o sujeito" (GALVÃO, 2012, p. 31); estudando “[...] a transformação da criança em adulto" (WALLON, 1975, p. 59).

Para isso, o autor aponta que essa transformação se dá em estágios ou etapas interdependentes, porém, não cumulativas; cada etapa configura novas possibilidades motoras, cognitivas e afetivas de a criança se relacionar com o entorno e consigo mesma, que são vistas em atividades as quais, ao mesmo tempo, constituem produto de conquistas recentes, mas que ainda convivem com atividades conquistadas anteriormente, ao mesmo tempo em que preparam novas possibilidades para o próximo estágio.

No entanto, cabe ressaltar que não é determinada faixa etária que estabelecerá quais atividades terão mais ou menos interesse, contudo, esses interesses e atividades dependerão muito dos estímulos que o ambiente (físico e social) fornecerá. Logo, admite-se que cada indivíduo tem uma trajetória distinta, e a duração de cada etapa do desenvolvimento é resultado das condições definidas por fatores de duas ordens: orgânica e social. Reconhece-se, dessa maneira, que a qualidade das relações estabelecidas com o ambiente físico e humano interfere no ritmo e forma do desenvolvimento. Nas palavras de Rodrigues (2008, p. 33), a cada estágio estabelecemse "[...] formas particulares de interação com o ambiente, onde processos cognitivos e afetivos desenvolvem-se integrados e influenciando-se reciprocamente: são construídos e se modificam de um período a outro, sofrendo ainda influência do ambiente cultural e social".

Nesse contexto, a relação entre os indivíduos (sujeito-sujeito) é vista como estímulo para o desenvolvimento e a aprendizagem infantil; na teoria walloniana, considera-se que, na relação entre os sujeitos, a marca significativa, ou elemento impulsionador, é a afetividade. Aprofundando-se nessa questão, Almeida (1999, p. 98) assinala que "[...] são as relações afetivas que medeiam a interação dos dois componentes do desenvolvimento humano: o orgânico e o social".

Sabendo-se que a afetividade é composta por um conjunto de manifestações, compreende-se que cada manifestação afetiva ocorre em seu tempo específico. Por

Educação, Psicologia e Interfaces, v. 2, n. 1, p. 88-104, Janeiro/Abril, 2018.

DOI: https://doi.org/10.37444/issn-2594-5343.v2i1.51 
Produções científicas sobre afetividade na relação adulto-criança no espaço da educação infantil

conseguinte, a primeira e mais expressiva manifestação que a criança utiliza, a fim de relacionar-se com seu entorno, é a emoção, a qual possui características de natureza orgânica e de natureza social, e que é percebida pela "[...] comunicação e mobilização do outro, durante o período inicial da vida (pelo choro ou agitação física, o bebê chama a atenção da pessoa que está por perto)" (TASSONI, 2006, p. 49).

Nessas manifestações, a afetividade, ao incorporar as construções da inteligência, tende a se racionalizar, ampliando suas formas de manifestação. A evolução decorrente seria a manifestação dos sentimentos, que só acontece com o aparecimento da capacidade simbólica, sendo então diferente das emoções, pois é menos intensa e visível, sendo mais profunda, duradoura e pensada pelo indivíduo.

Nesse sentido, há diferença de olhar a criança pelo prisma da teoria psicogenética walloniana, porque esta compreende a criança como um ser capaz de agir e interagir com o meio, tendo em vista as vicissitudes do momento do desenvolvimento em que se encontra. Dessa maneira, essa teoria, no entendimento da criança como um ser capaz, tem como referência os contextos específicos de cada indivíduo, trazendo, logo, a compreensão de não universalidade e linearidade das etapas do desenvolvimento (RODRIGUES, 2008).

Sobre essa questão, Rodrigues (2008, p. 32, grifo no original) ainda comenta que “[...] Wallon inaugura uma nova forma de conceber a motricidade, a afetividade, a inteligência e a gênese humana, elaborando uma 'psicogênese da pessoa completa', em aspectos de integração e contexto dos diferentes fatores constitutivos do indivíduo"; para esse autor, é a afetividade que propulsiona os processos psíquicos e não a inteligência, como foi proposto por outras teorias psicológicas.

Outro aspecto relevante acerca do ponto de vista walloniano sobre desenvolvimento psicológico humano é que essa teoria não persegue simplesmente o caminho percorrido pelo processo evolutivo do ser humano, todavia, busca compreender o processo de constituição do ser humano, numa perspectiva dialética. Assim, compreende o processo de desenvolvimento de modo não linear, marcado por rupturas, num caminho descontínuo, o qual passa por retrocessos e reviravoltas.

Portanto, cabe sustentar que o processo de desenvolvimento não se dá de forma calma para a criança. Há conflitos que ocorrem durante o desenvolvimento, que podem ser de origem exógena, quando resultantes de desencontros entre as ações da criança e o

Educação, Psicologia e Interfaces, v. 2, n. 1, p. 88-104, Janeiro/Abril, 2018 
ambiente exterior; e de ordem endógena, quando originados pelos efeitos da maturação nervosa; sendo esses propulsores do desenvolvimento humano (TASSONI, 2006).

Falar em conflitos é também falar em explosões emocionais, e a Educação Infantil é o lugar por excelência de conflitos dessa natureza; por isso, espera-se que o profissional que atua nesse espaço saiba lidar com a criança e seu processo de desenvolvimento afetivo-emocional, não para "dominar" as emoções das crianças, mas para encontrar formas saudáveis de favorecer o processo de compreensão de si mesma, por parte da criança (RODRIGUES, 2013).

\section{MATERIAL E MÉTODO}

Tendo em vista que o objetivo geral deste trabalho consiste em analisar como as pesquisas empíricas discutem a questão da afetividade na relação entre o educador e o educando, no ambiente da Educação Infantil, na perspectiva walloniana, adota-se a abordagem qualitativa de investigação, caracterizada ainda como estado do conhecimento. Segundo Ferreira (2002, p. 258), esse tipo de pesquisa visa "[...] mapear e discutir uma certa produção acadêmica em diferentes campos do conhecimento, tentando responder que aspectos e dimensões vêm sendo destacados e privilegiados $[\ldots]^{\prime \prime}$.

Dessa forma, como fonte de coleta de informações, foram selecionados os bancos virtuais: Scielo, Pepsic e o site da ANPEd. Interessa-nos destacar que, nos sitesScielo e Pepsic, delimitamos a busca de textos em periódicos das áreas de Educação e Psicologia avaliados com Qualis A e B, caracterizando pesquisas de significativa contribuição para as áreas em destaque. No que diz respeito ao site da ANPEd, foram selecionados apenas os trabalhos apresentados na modalidade de comunicação oral, nos Grupos de Trabalhos (GT) 07 - Educação de crianças de zero a seis anos de idade e 20 Psicologia da Educação. Cabe esclarecer que essas fontes foram escolhidas por disponibilizarem um vasto acervo sobre a área educacional, além de serem fontes consideradas confiáveis.

No que se refere à delimitação temporal da pesquisa, 2000 a 2012, esta ocorreu de sorte a privilegiar o ano em que a ANPEd passou a disponibilizar os trabalhos no seu site a última reunião anual realizada até o início da pesquisa, da $23^{\mathrm{a}}$ até a $35^{\mathrm{a}}$.

Educação, Psicologia e Interfaces, v. 2, n. 1, p. 88-104, Janeiro/Abril, 2018.

DOI: https://doi.org/10.37444/issn-2594-5343.v2i1.51 
Produções científicas sobre afetividade na relação adulto-criança no espaço da educação infantil

Quanto à busca dos textos nos periódicos, esta foi orientada por diferentes descritores, isolados e cruzados: afetividade, relação adulto-criança, relação educativa, relação professor-aluno, Wallon, walloniana, walloniano, Educação Infantil, emoção e relações interpessoais.

De início, foram selecionados 434 trabalhos, nos periódicos; um refinamento foi feito, limitando-se às publicações de somente duas grandes áreas do conhecimento, Psicologia e Educação, resultando em um número de 45 artigos. $\mathrm{O}$ passo seguinte foi fazer uma leitura mais detalhada do título e dos resumos das pesquisas, quando foram excluídos 39 trabalhos, restando apenas seis. A última etapa de seleção foi realizada a partir da leitura dos textos completos, quando foram selecionados para a análise final as pesquisas de Oliveira (2009) e de Reis (2005), um da área de Psicologia da Educação e outro de Educação.

No que concerne ao levantamento realizado no Portal da ANPEd, verificamos todos os trabalhos publicados no GT-07 - Educação da criança de 0 a 6 anos e no GT20 - Psicologia da Educação. No período analisado (2000-2012), foi publicado um total de 363 trabalhos nos dois GTs, dos quais, pela leitura do título, foram selecionados apenas 18. A partir da realização da leitura dos textos na íntegra, restaram apenas dois (BORBA; SPAZZIANI, 2007; RAMOS, 2011) trabalhos selecionados, ambos do GT 07, sendo um publicado no ano de 2007 e outro, em 2011.

Assim, ao final da etapa de organização dos materiais, antes do procedimento de análise propriamente dito, restaram apenas quatro trabalhos: dois encontrados nos anais da ANPEd e outros dois publicados em periódicos.

Isso posto, a seguir, trazemos a análise dos trabalhos com base em algumas categorias determinadas antes e durante as leituras, sendo elas: os referenciais teóricos adotados além da perspectiva walloniana; concepções de afetividade, de criança, de educador e de Educação Infantil assumidas pelos autores; e a existência ou não de proposta de ação e de trabalho quanto à temática em questão.

\section{RESULTADO E DISCUSSÃO}

Muitos pontos que orientam a discussão apresentada neste texto foram delimitados a partir dos trabalhos analisados; desse modo, cabe ressaltar que a análise feita procurou explorar as concepções explícitas e as concebidas nas entrelinhas, a fim

Educação, Psicologia e Interfaces, v. 2, n. 1, p. 88-104, Janeiro/Abril, 2018 
de se perceber as que realmente são definidas e defendidas em cada trabalho.

No que diz respeito ao referencial teórico dos quatro textos selecionados, além do uso da teoria walloniana para embasá-los, dois (REIS, 2005; BORBA; SPAZZIANI, 2007) recorrem também aos postulados vygotskyanos para esse fim, afirmando que tanto Wallon quanto Vygotsky acreditam que "[...] não se pode separar afetividade e cognição" (BORBA; SPAZZIANI, 2007, p. 4). Desses dois trabalhos, um (REIS, 2005) ainda elege a teoria piagetiana como complemento para a discussão do desenvolvimento infantil.É importante destacar que, apesar de usarem correntes epistemológicas diferentes, os trabalhos citados fazem "uma costura" coesa e coerente entre as ideias dos diferentes referenciais, apontando onde eles se encontram e onde se distanciam.

Já as outras duas pesquisas seguem articulações teóricas distintas; uma (RAMOS, 2011) traz a discussão da metodologia de pesquisa com crianças sugerida pela Sociologia da Infância, apresentando a criança como protagonista social e da investigação, o que pensamos não ser inadequado, pois as ideias dos distintos referenciais se "encaixam" harmoniosamente, se completam. A pesquisa de Oliveira (2009) adota, além das ideias wallonianas, a "Biologia do Amor" de Maturana e a psicologia de Jung; diferentemente dos trabalhos citados no primeiro grupo, este engloba diferentes concepções teóricas, de raízes epistemológicas distintas, justapostas, sem se articularem de maneira razoável. A autora chega a apresentar todas essas teorias em um único parágrafo, não deixando explícitas as possíveis diferenças existentes e pontos de aproximação entre um pressuposto e outro.

Assim, no que tange aos pressupostos teóricos adotados nos trabalhos analisados, percebe-se que, mesmo sendo a teoria walloniana acerca do desenvolvimento infantil, em si mesma, uma fonte significativa de conhecimento sobre o tema em questão, todas as pesquisadoras se impuseram o desafio de "costurá-la" com outros referenciais. No entanto, nem todas conseguiram realizar essa articulação de forma adequada.

Outro aspecto observado nos trabalhos tem a ver com o ponto de vista adotado; notou-se que os trabalhos focalizam ora um sujeito da relação, ora o outro, ou seja, as pesquisas enfatizam um dos atores: ou a criança ou o adulto/educador, e não a relação entre esses sujeitos.

Das quatro pesquisas analisadas, Reis (2005) e Ramos (2011) dão ênfase à

Educação, Psicologia e Interfaces, v. 2, n. 1, p. 88-104, Janeiro/Abril, 2018. 
Produções científicas sobre afetividade na relação adulto-criança no espaço da educação infantil

criança, sendo que uma procura compreender o que as crianças conseguem verbalizar sobre suas lembranças da época em que frequentavam a pré-escola, enquanto a outra analisa a relação estabelecida entre criança e adulto, em um berçário, de forma a interpretar as expressões das crianças na participação ativa na construção do currículo.

Reis (2005, p. 65) considera a criança “[...] como um sujeito social e histórico, como um cidadão de pouca idade, constituído de dimensões múltiplas e diferenciadas, com direito a um processo de desenvolvimento pleno e harmônico". Nessa mesma perspectiva, o trabalho de $\operatorname{Ramos}(2011$, p. 1) afirma que a criança,

[...] em suas experiências, relações com outros sujeitos, sejam adultos, parceiros de idade ou não, são capazes de agir/refletir sobre o que produzem e o que vivenciam culturalmente. [...] assumem um lugar ativo de produtoras de culturas, vivendo intensos processos de relações e transformações, sempre a reelaborar novos/outros significados e a produzir condições de criação fundadas em suas relações sociais.

Acreditamos que os trabalhos examinados, os quais se propõem dar ênfase ao ponto de vista infantil, realmente o fazem, contemplando o entendimento da criança como protagonista, revelando compreender e levar em conta as especificidades das capacidades infantis em plano privilegiado.

Nessa direção, no que diz respeito à percepção dos autores dos textos analisados acerca da infância, os dois trabalhos que protagonizam a criança concebem a infância como "[...] uma etapa particular do ciclo vital do ser humano" (REIS, 2005, p. 65) e ainda como "um grupo social" (RAMOS, 2011, p. 1), reconhecendo a complexidade e a particularidade da infância. Desse modo, percebe-se a preocupação em evidenciar uma concepção que não destoe do aporte teórico walloniano, pois, segundo Mahoney e Almeida (2004, p. 13), nesse referencial, “[...] a infância é considerada pela teoria de uma perspectiva funcional, isto é, como um período claramente diferenciado, com necessidades e características próprias, e cuja função primordial é a constituição do adulto".

Quanto aos outros dois trabalhos ${ }^{1}$ que focam o educador/adulto, um deles apresenta um projeto de formação continuada para profissionais da Educação Infantil, enquanto o outro evidencia uma pesquisa com o objetivo de descobrir qual a concepção

${ }_{1}^{1}$ OLIVEIRA, 2009; BORBA; SPAZZIANI, 2007.

Educação, Psicologia e Interfaces, v. 2, n. 1, p. 88-104, Janeiro/Abril, 2018 
de afetividade que os educadores da Educação Infantil possuem.

É possível, então, afirmar que os trabalhos analisados compartilham a concepção de educador com o prisma walloniano, enfatizando assim este como "[...] principal mediador em sala de aula [...]" (BORBA; SPAZZIANI, 2007, p. 14-15). Nesse sentido, o trabalho de Reis (2005) sustenta que o educador deve "[...] criar as condições facilitadoras do acesso a vivências com os conhecimentos socioculturais valorizados socialmente e criar ambiente e espaço para a concretização dessas experiências” (p. 58 59); e, ainda, deve "[...] ouvir o aluno para conhecer melhor suas expectativas, necessidades e interesses, suas formas próprias de pensar, sentir e agir, como aspectos fundamentais no planejamento da tarefa pedagógica" (p. 74).Ainda na mesma perspectiva, de acordo com Ramos (2011, p. 12), o educador da Educação Infantil precisa ser

[...] sujeito crítico que reconhece a dimensão política e educativa de seu fazer enquanto parceiro crítico-reflexivo na implementação da qualidade na educação à criança que pode se consolidar em parceira com a escuta da criança pelo viés do conhecimento das especificidades e competências infantis. (RAMOS, 2011, p. 12).

Tanto o entendimento do papel do profissional de ouvir e observar os aprendizes quanto aquele relacionado ao caráter político da profissão docente se aproximam do pensamento walloniano, quando se evidencia em seu pressuposto que "[...] a teoria é, portanto, um suporte necessário à função de observador; o professor só poderá ler, e consequentemente interpretar, aquilo que observa com base em um referencial". Desse modo, exercerá seu papel de “[...] mediador do processo de evolução da afetividade da criança”, considerando nesse trabalho que a evolução afetiva colabora com a cognitiva e vice-versa, de maneira que o educador seria mediador também no processo de desenvolvimento cognitivo (ALMEIDA, 1999, p. 16-17).

Em relação à concepção de Educação Infantil, três trabalhos compartilham explicitamente o conceito de Educação Infantil realçado nos pressupostos teóricos wallonianos. Na mesma medida, Ramos (2011, p. 11) aponta que a Educação Infantil deve

[...] oferecer a ajuda necessária para o desenvolvimento das idéias da criança, apoiá-las na interpretação de suas ações, na ressignificação de seus atos, são pontos importantes num ambiente pedagógico que

Educação, Psicologia e Interfaces, v. 2, n. 1, p. 88-104, Janeiro/Abril, 2018.

DOI: https://doi.org/10.37444/issn-2594-5343.v2i1.51 
Produções científicas sobre afetividade na relação adulto-criança no espaço da educação infantil

considera e impulsiona o modo próprio de agir, de pensar e de sentir da criança.

Para Reis (2005, p. 70), o ambiente educacional, mais especificamente a Educação Infantil, é compreendida como “[...] um contexto de socialização para a criança, diferenciado da família no que se refere aos padrões de comportamento exigidos dos sujeitos e que são característicos da instituição”. Analogamente, no terceiro trabalho, a ideia de Educação Infantil é a de que

[...] se constitua num espaço onde as formas de expressão da criança, [...], dentre elas, alinguagem verbal e corporal ocupe lugar privilegiado. Num contexto lúdico e prazeroso de jogos e brincadeiras, [...], objetiva-se promover o desenvolvimento individual, social e cultural [...] (BORBA; SPAZZIANI, 2007, p. 15).

Acreditamos que as concepções expostas acima são compatíveis com os pressupostos teóricos wallonianos, para os quais, segundo Almeida (1999, p. 99),

[...] a escola desempenha um papel fundamental no desenvolvimento socioafetivo da criança. Como meio social, é um ambiente diferente da família, porém bastante propício ao seu desenvolvimento, pois é diversificado, rico em interações, e permite à criança estabelecer relações simétricas entre os parceiros da mesma idade, e assimétricas com adultos.

No que se refere ao conceito de afetividade, três trabalhos o trazem de forma explícita, conforme pode ser visualizado nos trechos a seguir:

A afetividade é fator fundamental na constituição do sujeito. É entendida como instrumento de sobrevivência do ser humano, pois corresponde à primeira manifestação do psiquismo, propulsiona o desenvolvimento cognitivo ao instaurar vínculos imediatos com o meio social [...] (BORBA; SPAZZIANI, 2007, p. 2).

As experiências vivenciadas pelas crianças nas instituições educativas (creche, pré-escola ou escola) trazem em si sentimentos, afetos, valores, representações que podem favorecer ou dificultar o processo de escolarização (REIS, 2005, p. 60).

São várias as situações em que o professor precisa lidar com aspectos da afetividade infantil: a separação da mãe; a adaptação a um espaço coletivo de convivências; as muitas tarefas de higiene, alimentação, sono, entre tantos outros cuidados e ações pedagógicas (OLIVEIRA, 2009, p. 94).

De outra maneira, no trabalho de Ramos (2011, p. 3), inferimos que, pelo trecho a seguir, está implícita uma ideia do que seja afetividade, para a autora:

Educação, Psicologia e Interfaces, v. 2, n. 1, p. 88-104, Janeiro/Abril, 2018

DOI: https://doi.org/10.37444/issn-2594-5343.v2i1.51 
[...] ao situar a criança em berçários, essas ideias ganham contornos específicos. Isso porque é necessário romper com a lógica que identifica a criança dessa faixa como imatura socialmente. Apesar de sua dependência do adulto para sobreviver, os bebês e as crianças bem pequenas são extremamente capazes de tomar iniciativas e agir, dispondo de amplos recursos, desde que nascem, para interagir com e no mundo.

É importante destacar que esse fragmento também traz considerações sobre a crença na capacidade da criança de transformar situações postas pelo adulto no ambiente educacional, entendimento compartilhado entre a teoria walloniana e o movimento da Sociologia da Infância. Nessa direção, Delgado (2013, p. 24-25) afirma que as crianças são "[...] atores sociais e competentes nas relações sociais que vivem no mundo, as crianças não se limitam a aprender e cumprir as normas impostas pelos adultos, pois assumem papéis de resistência”.

Com isso, entendemos que é importante considerar a afetividade como recurso para a interação entre criança e mundo, pois as crianças do berçário ainda estão no estágio descrito por Wallon como impulsivo-emocional, no qual ainda não utilizam a fala para se comunicar; no entanto, dispõem de outras formas de expressão, conforme ressalta Galvão (2003, p. 72), ao mencionar que a criança com “[...] sua imperícia em agir sobre as coisas é compensada por sua exuberância expressiva, extremamente eficiente na relação com as pessoas".

Desse modo, mesmo que os trabalhos não usem claramente a palavra "afetividade", é possível inferir que consideram sua dinâmica, em específico a proposta pela teoria walloniana, como um fator fundamental para o processo de desenvolvimento infantil, quando assumem que os sentimentos e afetos presentes nas experiências vivenciadas pelas crianças podem facilitar ou não a aprendizagem, pressupondo que as relações firmadas entre educador e aprendiz são carregadas de afetividade. Portanto, pode-se afirmar que todos os trabalhos analisados possivelmente entendem e consideram a importância da dimensão afetiva, no ambiente educativo.

É unânime entre os trabalhos conceber a emoção como meio de comunicação e expressão para e com o mundo. Nessa linha, as autoras ponderam a importância da emoção para o desenvolvimento infantil, aspecto que fica explícito nos seguintes trechos:

Educação, Psicologia e Interfaces, v. 2, n. 1, p. 88-104, Janeiro/Abril, 2018.

DOI: https://doi.org/10.37444/issn-2594-5343.v2i1.51 
As relações de um recém-nascido com o ambiente são de natureza afetiva-emocional. São de emoção as primeiras manifestações sociais da criança, que permitem o desenvolvimento da linguagem e tornam possíveis as representações [...] (REIS, 2005, p. 60).

[...] é possível apoiar as aquisições sociocomunicativas da criança, reconhecendo-a enquanto sujeito socialmente competente e capaz de organizar suas percepções e expressá-las criativamente com recursos não-verbais [...] (RAMOS, 2011, p. 11).

Nestas relações interpessoais a emoção tem papel fundamental, pois é ela que possibilita ao bebê provocar ajuda do outro, garantindo sua sobrevivência. São suas emoções que a unem ao meio social (BORBA; SPAZZIANI, 2007, p. 4).

[...] através das reações corporais do bebê, as quais exercem essa função de manifestar emoções e mobilizar o adulto para atender às suas necessidades [...] (OLIVEIRA, 2009, p. 95).

Assim, pressupõe-se que o profissional docente, ao se assumir como adulto mais experiente, esteja atento tanto a si quanto ao outro, de forma equilibrada, dispondo de maiores recursos para controle das emoções e sentimentos, de sorte a poder na resolução dos conflitos que surgem rotineiramente no ambiente de aprendizagem nos diferentes níveis (MAHONEY; ALMEIDA, 2007).

Sobre isso, Almeida (1999, p. 106) argumenta que “[...] a relação professoraluno, por ser de natureza antagônica, oferece riquíssimas possibilidades de crescimento. Os conflitos que podem surgir dessa relação desigual exercem um importante papel na personalidade da criança".

Dois trabalhos analisados acham fundamental para o desenvolvimento e aprendizagem infantil o contexto social, o ambiente de cada indivíduo, assim compreendendo a importância dada por Wallon ao meio, conforme discutido anteriormente. Desse modo, os textos examinados afirmam que os diferentes ambientes sociais favorecem a socialização, apontando que:

[...] o processo de socialização resulta da interação da criança com os recursos de seu meio e depende tanto das características da própria criança, quanto das formas de agir dos parceiros da relação. A socialização é, neste sentido, um processo interativo por meio do qual a criança satisfaz suas necessidades básicas e assimila a cultura do seu grupo (REIS, 2005, p. 70).

A interação social é fator fundante dos processos psicológicos superiores e estes se constituem da indissociabilidade entre afeto e cognição (BORBA; SPAZZIANI, 2007, p. 1).

Uma das questões que guia este trabalho diz respeito às possíveis sugestões de ação contidas nos textos analisados, quanto à temática discutida nesta investigação.

Educação, Psicologia e Interfaces, v. 2, n. 1, p. 88-104, Janeiro/Abril, 2018 
Acreditamos que as intervenções indicadas, em sua maioria, tomam o conhecimento como suporte, se não suficiente, necessário para a prática educativa, porque, com a construção do conhecimento, ampliam-se as possibilidades de compreensão de nossa realidade, e o educador consegue identificar os fatos que acontecem corriqueiramente, na sala de aula.

Portanto, é possível asseverar que todos os trabalhos, ao problematizar pontos significativos da teoria walloniana sobre a afetividade e, consequentemente, sobre o desenvolvimento psicológico humano, utilizam a teoria como fonte de conhecimento para embasar tanto pesquisas quanto práticas pedagógicas, favorecendo a articulação entre teoria e prática. Logo, pensamos que todos os trabalhos trazem importantes contribuições para a reflexão sobre o trabalho docente.

\section{CONSIDERAÇÕES FINAIS}

Diante do que foi evidenciado ao longo deste trabalho, surgem questões que merecem destaque. A primeira é atinente ao número de trabalhos encontrados e submetidos à análise, pelo qual ficou perceptível que a temática problematizada neste trabalho ainda não é muito estudada no cenário da Educação Infantil, pensando-se especificamente na pesquisa empírica. Todavia, não é possível afirmar que a afetividade envolvida na relação entre o educador e o aprendiz, na perspectiva walloniana, não é estudada, porque, na primeira etapa de levantamento dos dados, encontramos um número relevante de pesquisas em outros ambientes, como o das séries iniciais do Ensino Fundamental.

De qualquer maneira, restaram alguns questionamentos, tais como: há falta de preocupação dos pesquisadores em estudar ou aprofundar seus conhecimentos sobre o assunto? Será que a relação educador-aprendiz, no tocante à afetividade, não tem tanta importância na Educação Infantil? Por que muitas pesquisas teóricas contrastam com um número reduzido de pesquisas empíricas sobre a temática? Qual(is) a(s) dificuldade(s) em se realizar uma pesquisa empírica sobre as manifestações envolvidas na relação adulto-criança, no cenário da Educação Infantil?

Em decorrência, apesar de a análise feita na perspectiva quantitativa assinalar preocupações, a análise qualitativa foi satisfatória, porque foi possível notar que, nos 
Produções científicas sobre afetividade na relação adulto-criança no espaço da educação infantil

trabalhos, havia a apropriação do conceito walloniano de afetividade, tendo em vista seu conhecimento e uso como elemento de extrema importância, no ambiente educacional.

Cabe ressaltar que a relação entre o adulto e a criança é muito enfatizada, na medida em que os trabalhos se preocuparam em contemplar propostas de ação e de trabalho, as quais priorizem a afetividade, na relação do educador e de aprendiz. Cada um dos textos analisados contemplou, conforme seus objetivos, o trabalho pedagógico voltado às relações estabelecidas no ambiente de aprendizagem.

Outro ponto importante diz respeito aos referenciais que os trabalhos analisados adotaram, para subsidiar teoricamente as pesquisas. É possível assegurar que, a despeito de ter optado pela utilização de mais autores, a escolha por adotar, em alguns casos, o mínimo de proposições da teoria walloniana como embasamento teórico já é em si significativa para a propagação do conhecimento acerca do desenvolvimento infantil, na perspectiva que concebe a criança como ser ativo e completo, em momento peculiar do desenvolvimento, num movimento constante e dialético, trazendo assim contribuições para a mudança na maneira de olhar e compreender as condutas das crianças.

Sobre isso, cabe salientar que a escolha de um referencial - ou até mesmo de mais que um - para se fundamentar é de suma importância para a prática educativa e para a construção de um texto científico, todavia, é relevante frisar que as junções das teorias devem acontecer de forma que se complementem coerentemente ou até mesmo que seja possível fazer certas aproximações, de maneira clara e específica.

No que diz respeito às práticas pedagógicas, refletir sobre a relação entre o adulto e a criança no ambiente educacional, particularmente na Educação Infantil, é pensar em um fazer pedagógico que considere o desenvolvimento e a aprendizagem integrais e integrados, de forma que se possibilite ao profissional lidar de maneira significativa e qualitativamente positiva com as manifestações afetivas as quais envolvem as relações estabelecidas nos ambientes de aprendizagem, considerando não só a relação entre o educador e o aprendiz, mas também a relação entre as crianças, que é igualmente de suma importância para o processo de desenvolvimento e aprendizagem. Desse modo, pensar no aprendiz como ser total é colocar em prática uma educação que privilegie não o provimento de conhecimentos, mas a formação das mentalidades e personalidades, compreendendo que a escola deve procurar articular as diferentes dimensões das crianças, de sorte a promover o desenvolvimento integral e

Educação, Psicologia e Interfaces, v. 2, n. 1, p. 88-104, Janeiro/Abril, 2018 
pleno do sujeito aprendiz (ALMEIDA, 1999).

Enfim, cabe reafirmar que o conhecimento sobre a afetividade que permeia as relações interpessoais, conforme concebido por Henri Wallon, pode proporcionar ricos subsídios para uma prática que não encare a afetividade de um ponto de vista simplista, apenas como manifestação de carinho ou em seu aspecto positivo, mas percebendo-a como uma dimensão subjetiva do indivíduo indissociável da dimensão objetiva (cognição) nas diversas atividades implementadas no ambiente de aprendizagem.

\section{REFERÊNCIAS BIBLIOGRÁFICAS}

ALMEIDA, A. R. S. A emoção na sala de aula. Campinas: Papirus, 1999.

BORBA, V. R. S.; SPAZZIANI, M. de L. Afetividade no contexto da Educação Infantil. In: REUNIÃO ANUAL DA ANPED, 30, 2007, Caxambu.Anais... Caxambu: ANPEd, 2007. p. 1-18. Disponível em:http://www.anped.org.br/reunioes/30ra/trabalhos/GT07-3476--Int.pdf 28/11/2012. Acesso em: 28 nov. 2012.

DELGADO, A. C. C. A emergência da Sociologia da Infância em Portugal. Revista Educação - Especial Cultura e Sociologia da Infância. São Paulo, p. 14-27, 2013.

FERREIRA, N. S. de A. As pesquisas denominadas "Estado da arte". Educação e Sociedade, Campinas, Ano XXIII, v. 23, n. 79, ago. 2002.

GALVÃO, I. Expressividade e emoções segundo a perspectiva de Wallon. In: ARANTES, V. A. (Org.). Afetividade na escola:alternativas teóricas e práticas. São Paulo: Summus, 2003. p. 71-88.

GALVÃO, I. Henri Wallon: uma concepção dialética do desenvolvimento infantil. Rio de Janeiro: Vozes, 2012.

MAHONEY, A. A.; ALMEIDA, L. R. (Org.) A constituição da pessoa na proposta de Henri Wallon. São Paulo: Loyola, 2004.

MAHONEY, A. A.; ALMEIDA, L. R. (Org.) Henri Wallon psicologia e educação. 7. ed. São Paulo: Loyola, 2007.

OLIVEIRA, M. K.; REGO, T. C. Vygotsky e as complexas relações entre cognição e afeto. In: ARANTES, V. A. (Org.). Afetividade na escola: alternativas teóricas e práticas. São Paulo: Summus, 2003. p. 13-34.

OLIVEIRA, R. P. Tocar e trocar... o corpo, o afeto, a aprendizagem: uma experiência de formação continuada em um Centro de Educação Infantil. Construção psicopedagógica, v. 17, n. 15, p. 91-110, dez. 2009. Disponível em: 
http://pepsic.bvsalud.org/pdf/cp/v17n15/v17n15a07.pdf. Acesso em: 26 nov. 2012.

RAMOS, T. K. G. Possibilidades de organização de práticas educativas na creche em parceria com os bebês: o que "dizem" as crianças? In: REUNIÃO ANUAL DA ANPED, 34, 2011, Caxambu. Anais... Caxambu: ANPEd, 2011. p. 1-16. Disponível em: http://34reuniao.anped.org.br/images/trabalhos/GT07/GT07-1092\%20int.pdf.

Acesso em: 28 nov. 2012.

REIS, R. M. C. A pré-escola na visão de crianças de $1^{\text {a }}$ série. Psicologia da Educação, n. 20, p. 55-75, jun. 2005. Disponível em: http://pepsic.bvsalud.org/pdf/cp/v20n20/05.pdf. Acesso em: 05 ago. 2013.

RODRIGUES, S. A. Expressividade e emoções na primeira infância:um estudo sobre a interação criança-criança na perspectiva walloniana. 2008. Dissertação (Mestrado em Educação) - Faculdade de Ciências e Tecnologia, Universidade Estadual Paulista, Presidente

Prudente, 2008.

RODRIGUES, S. A. Reflexões sobre a organização de práticas educativas no contexto da Educação Infantil.Nuances: estudos sobre Educação. Presidente Prudente, n. 25, v. 01, p. 183-199, jan./abr. 2013.

TASSONI, E. C. M. Dimensões afetivas na relação professor-aluno. In: LEITE, S. A. S. (Org.). Afetividade e práticas pedagógicas. São Paulo: Casa do Psicólogo, 2006. p. 47-73.

WALLON, H. Psicologia e educação da infância. Lisboa: Estampa, 1975.

Credenciais das autoras

SILVA, Fernanda Ribeiro. Graduada em Pedagogia pela Universidade Federal do Mato Grosso do Sul - Câmpus do Pantanal; Professora da Rede Municipal de Ensino de Ladário-MS. E-mail: fernandardas@gmail.com

RODRIGUES, Sílvia Adriana.Doutora em Educação; Professora da Universidade Federal do Mato Grosso do Sul - Câmpus do Pantanal e do Campus de Três Lagoas Email: silvia.rodrigues@ufms.br

Endereço para correspondência: Fernanda Ribeiro da Silva.Rua Presidente Juscelino Kubitschek, n.436, CEP: 79370-000, Cidade Ladário, MS.E-mail: fernandardas@ gmail.com

Como citar este artigo (Formato ABNT): SILVA, Fernanda Ribeiro; RODRIGUES, Sílvia Adriana. Produções científicas sobre afetividade na relação adulto-criança no espaço da educação infantil. Educação, Psicologia e Interfaces, v. 2, n.1, 88-104, 2018. DOI: https://doi.org/10.37444/issn-2594-5343.v2i1.51

Recebido: 06/01/2018.

Aceito: 26/01/2018.

Educação, Psicologia e Interfaces, v. 2, n. 1, p. 88-104, Janeiro/Abril, 2018 